\title{
Avoiding Plagiarism and Self-Plagiarism
}

\author{
Prof. Neelam Adhikari
}

Rector, PAHS

$\mathrm{M}$

edical publications are often produced when an author wants to say something important, which may or may not change established medical practice or to describe a new finding. They are also made to describe findings in local contexts, even though the subject matter may be well described in the context of other places.

"Plagiarism is taking over the ideas, methods, or written words of another, without acknowledgment and with the intention that they be taken as the work of the deceiver." ${ }^{1}$ In the medical context, plagiarism is common among medical students to senior doctors alike. In essence, it is a serious medical misconduct amounting to fraud and literary theft. In the sciences, when we borrow someone's idea, explanation, theory or writing, we must give proper references. Sometimes especially amongst young and new writers, lack of knowledge about when and how to make a reference citation unknowingly lead to plagiarism.

Fortunately frequency of misconduct occurs less often in serious misconduct situations ${ }^{2}$.

Lots of papers are written and published in peerreviewed journals as a necessity for appointment and gaining promotion for academicians. This is particularly the case with the recent increase in medical institutions, medical journals, students and academicians in Nepal. Those with more publications to their credit have more chances of appointment and promotion. Some are under immense pressure and consider publishing a pressing urgency. This is the reason that concept of keeping Teaching Portfolios by academics is getting more popular. Portfolios not only demonstrate and give credit to publications, they also demonstrate quality of teaching and patient care (for clinicians) ${ }^{3}$.

Is it possible to self plagiarize? After all one cannot steal from himself/herself. But the answer is that yes, it is possible. There are four possible types of selfplagiarism².
1. Salami-Slicing: The author publishes the same or part of the material published before elsewhere with some changes in its presentation. This type of deceit is called Salami-Slicing. The reader has not been told that similar material has been published elsewhere.

2. Redundant/duplicate publication: When an author is in a hurry to get published he or she may submit the same material to more than one place at the same time, thinking that it will most probably not be published. But the article gets published in two places (redundant/duplicate publication). There may be minor changes in abstract, title and order of authors and content of the paper. Most of the major scientific writing guides caution against this practice. Medical papers require an affirmation at the time of submission that the material is not previously published or is simultaneously being submitted elsewhere. The authors must honor the undertaking.

3. Copyright infringement: This is a less understood form of plagiarism. When an author publishes in a journal, the copyright of the author's work gets transferred to the publisher. The unauthorized duplication of work is copyright infringement. "In the case of "Open Access" journals (freely available to the public without expectation of payment), the author agrees to allow for the free dissemination of his/her works without prior permission." ${ }^{4}$ Sometimes exceptions are made to copyright rule for nonprofit educational purposes. In some situations, a student may copy a chapter or the whole book after receiving permission. Some journal and books are also available on Internet for free downloads. This falls under the doctrine of "Fair use" (US copyright office fair use $)^{5}$.

4. Text recycling: When a research is done at two places with similar methodology, using substantial chunks of the previous study -- including abstract, introduction and methodology -- is called text 
cycling and falls under self-plagiarism and is not acceptable.

Self-plagiarism is detrimental to scientific progress. Journals and conferences have many papers of similar types and relevant true findings get difficult to find. It also gives credit to the authors who break down their papers in small units as their number of published articles increase. Finally, reputed journals have limited space. When a self-plagiarized article is published, another, more deserving article is not. Our editors should be able to train themselves and use SPLaT tool for detection of self- plagiarism 6 . However this tool can only be used for indexed journals. Many Nepali journals are not indexed at this time; therefore this tool has limited use for now.

The SplaT (Self Plagiarism detection Tool) functions in three modes:

1. Web Spider mode: SPLaT crawls through web sites from specified top fifty Computer Science Departments. This is used to detect self-plagiarism by computer science academics.

2. Reviewer's workbench mode: SPLaT compares a paper under review to the record of an author's publications from their websites and online repositories.

3. Author mode: SPLaT detects the author's selfplagiarism when the same paper is published twice in different journals at an interval.

SPlaT tool can be downloaded at splatapp.zip. There are inbuilt tutorials of the system.

SPlaT Java source code can be downloaded at splat.zip. SplaT results can be viewed at screen shots.

This tool generates warnings. All instances must be reviewed by the reviewer/editor.

Authors and editors should both try to adhere to professional standards or others will do it for us. More education is needed. Practice of keeping a Teaching Potfolio should be encouraged. Let us take this issue very seriously.

\section{References}

1. American Association of University Professors. September/October, 1989.

2. Hexham Irving: Academic plagiarism defined. Department of Religious Studies University of Calgary. Copyright Irving Hexham 1992, 1999, 2005

3. Peter Seldin. The Teaching Portfolio. A Practical Guide to Improved Performance and Promotion / Tenure Decisions. $3^{\text {rd }}$ Ed.2004. page 2.

4. Miguel Roig. Office of Research Integrity US department of Health and Human Services. Avoiding plagiarism, self-plagiarism and other questionable writing practicing, 2005. (PDF of module is down loadable)

5. The American Medical Association's Manual of Style (Iverson, et al., 1998)

6. Christian Collberg, Stephen Kobourov, Joshua Louie, Thomas Slattery, SPlaT: A System for Self-Plagiarism Detection, IADIS International Conference WWW/INTERNET 2003, Algarve, Portugal 5-8 November 2003.

\section{Suggested readings}

1. The Chicago Manual of Style (Chicago, Chicago University Press, 2003, first edition 1949).

2. Kate L. Turabian's A Manual of Style for Writers (Chicago, Chicago University Press, 1996, first edition 1963), The Canadian Style: A Guide to Writing and Editing (Secretary of State, Toronto: Dundurn Press, 1985). 